\title{
Ultrasound Assessment of Kidney Volume in Patients with Acute Decompensated Heart Failure: A Predictor of Diuretic Resistance
}

\author{
Shinobu Sugihara,* Yoshiharu Kinugasa,* Tomoaki Takata, $\dagger$ Takaaki Sugihara, $\dagger$ Keiko Hosho, $\dagger$ Chitose Imai, \\ Hiromi Ito, $\$$ Kensaku Yamada,* Masahiko Kato* and Kazuhiro Yamamoto* \\ *Division of Cardiovascular Medicine, Department of Molecular Medicine and Therapeutics, School of Medicine, Tottori University \\ Faculty of Medicine, Yonago 683-8503, Japan, †Division of Medicine and Clinical Science, Department of Multidisciplinary Internal \\ Medicine, School of Medicine, Tottori University Faculty of Medicine, Yonago 683-8503, Japan, $\$$ Division of Clinical Laboratory Med- \\ icine, Department of Pathophysiological and Therapeutic Science, School of Medicine, Tottori University Faculty of Medicine, Yonago \\ 683-8503, Japan, and §Department of Clinical Radiology, Tottori University Hospital, Yonago 683-8504, Japan
}

\section{ABSTRACT}

Background Diuretics are essential for treating acute decompensated heart failure (ADHF), but the response is inconsistent. This study aimed to clarify whether kidney volume as assessed by ultrasound (US) predicts diuretic resistance in patients with ADHF.

Methods We enrolled 29 patients with ADHF and 32 controls. Height-adjusted kidney volume was assessed by US. We divided patients into two groups based on the median value of total daily use of furosemide (intravenous dose plus $0.5 \times$ oral dose of furosemide equivalents) during 3 days from admission.

Results Patients with ADHF had a significantly smaller left kidney volume than did control subjects $(27.7 \pm$ 10.0 vs. $32.8 \pm 8.8 \mathrm{~mL} / \mathrm{m}, P<0.05)$. Patients in the highdose furosemide group ( $\geq 51.7 \mathrm{mg} / \mathrm{d}$ ) had a significantly lower estimated glomerular filtration rate (eGFR) and a significantly smaller kidney volume than did those in the low-dose furosemide group (eGFR: $43.9 \pm 20.4$ vs. 60.8 $\pm 21.6 \mathrm{~mL} / \mathrm{min} / 1.73 \mathrm{~m}^{2}$, left kidney volume: $23.2 \pm 5.2$ vs. $32.6 \pm 11.0 \mathrm{~mL} / \mathrm{m}$, right kidney volume: $26.5 \pm 7.5$ vs. $32.6 \pm 7.9 \mathrm{~mL} / \mathrm{m}$, all $P<0.05$ ). Multivariate logistic analysis showed that left kidney volume, but not eGFR, was independently associated with the requirement of high-dose furosemide (odds ratio: $0.856,95 \%$ confidence interval: 0.735-0.997, $P<0.05$ ).

Corresponding author: Shinobu Sugihara, MD, $\mathrm{PhD}$

shinobutozuito@gmail.com

Received 2017 May 31

Accepted 2017 June 21

Abbreviations: ACEI, angiotensin-converting enzyme inhibitor; $\mathrm{ADHF}$, acute decompensated heart failure; ARB, angiotensin receptor blocker; BNP, B-type natriuretic peptide; BUN, blood urea nitrogen; CKD, chronic kidney disease; CT, computed tomography; D, depth; eGFR, estimated glomerular filtration rate; ESC, European Society of Cardiology; IABP, intra-aortic balloon pumping; IAP, intra-abdominal pressure; i.v., intravenous; JVD, jugular vein dilation; L, length; LVEF, left ventricular ejection function; MRA, Mineralocorticoid receptor antagonist; NPPV, noninvasive positive pressure ventilation; PCPS, percutaneous cardiopulmonary support; US, ultrasound; W, width
Conclusion Kidney volume as assessed by US is a useful predictor of diuretic resistance in patients with ADHF.

Key words acute decompensated heart failure; diuretic resistance; kidney volume; ultrasound examination

A lack of adequate relief of symptoms is associated with a longer hospital stay and increased mortality. Therefore, early and effective decongestion for improving outcomes in acute decompensated heart failure (ADHF) is important. ${ }^{1,2}$ Intravenous furosemide is currently prescribed for approximately $90 \%$ of hospitalized patients with ADHF to relieve congestion. ${ }^{3}$ However, there is an ADHF subpopulation with diuretic resistance who are at high risk for morbidity and mortality. ${ }^{4}$ Previous studies have shown that renal impairment is one of the determinants of a poor diuretic response in patients with ADHF. ${ }^{5-8}$ In a stable hemodynamic state, serum creatinine levels, estimated glomerular filtration rate (eGFR), and blood urea nitrogen (BUN) levels are good parameters for renal function. ${ }^{9}$ However, in ADHF, several factors affect the value of these renal biomarkers ${ }^{7,10,11}$ and a conventional renal function test may be insufficient to identify patients at high risk for diuretic resistance..$^{12,13}$

Kidney volume is decreased with glomerular sclerosis and tubular atrophy. Kidney volume is a simple estimate of renal reserve and function in patients with suspected renal diseases. ${ }^{14}$ However, the relationship between kidney size and diuretic resistance in ADHF remains unknown. The present study aimed to clarify whether kidney volume as assessed by ultrasound (US) predicts diuretic resistance in patients with ADHF.

\section{SUBJECTS AND METHODS Subjects}

The present study enrolled 29 consecutive patients with ADHF who were hospitalized in Tottori University Hospital from April 2014 to November 2015. They agreed to participate in this study within 48 hours after 
A
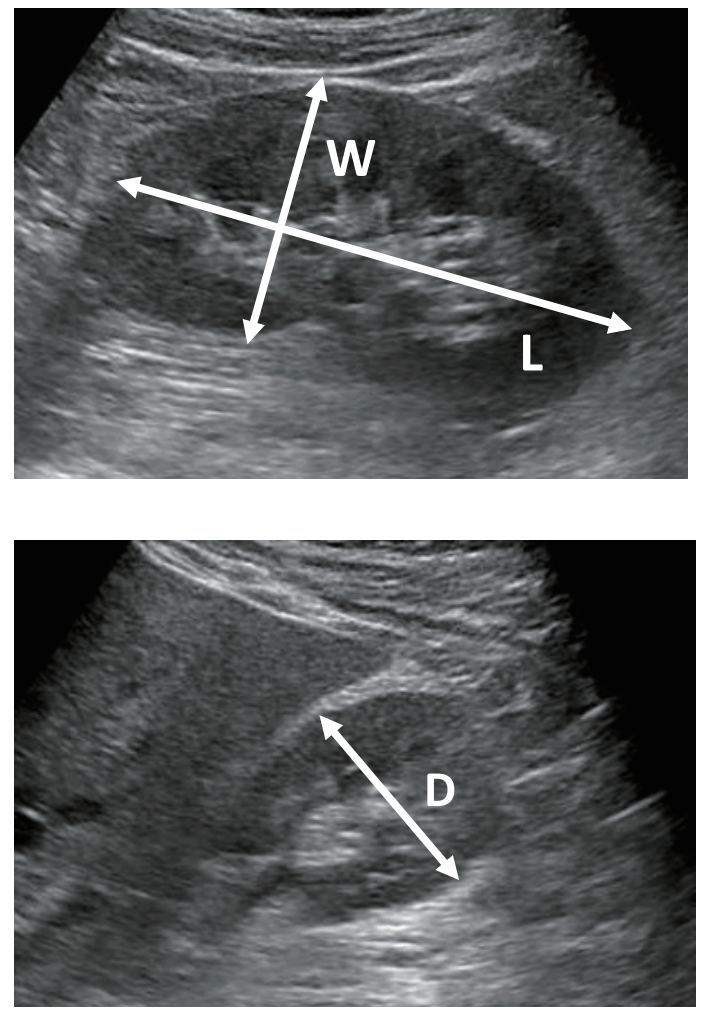

B

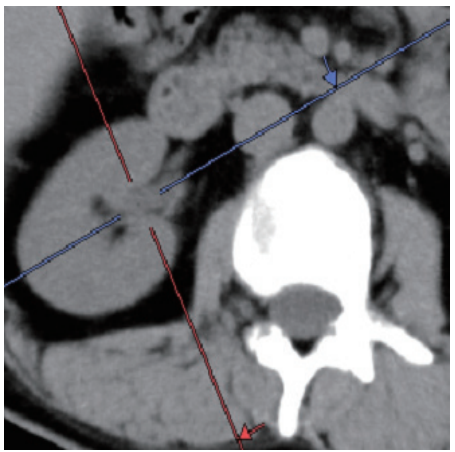

C

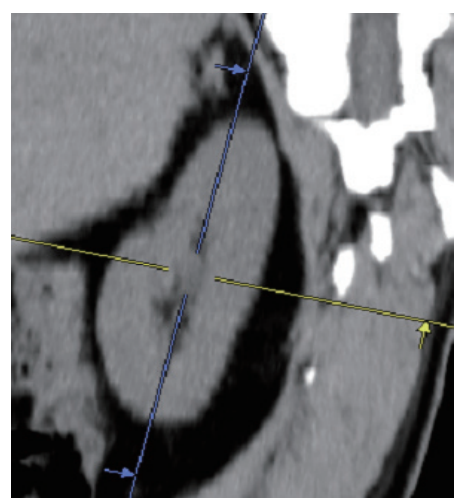

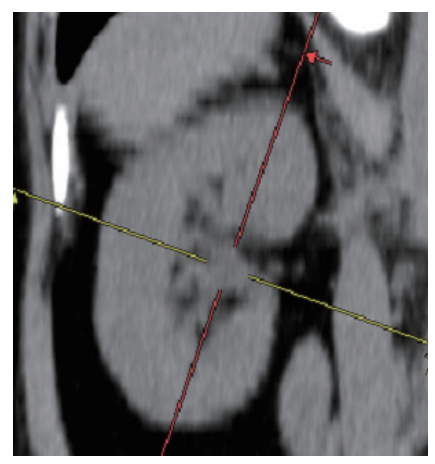

d

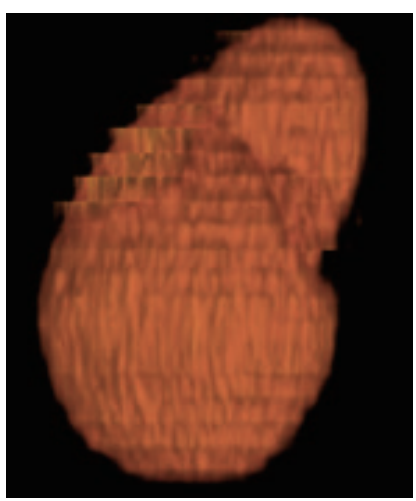

Fig. 1. Representative ultrasonic images and computed tomography images for measurement of kidney size. A: Representative ultrasonic images. B: Representative computed tomography images, $\mathbf{a}$ : axial image, b: coronal image, c: sagittal image, and d: three-dimensional reconstructive image. $\mathrm{D}$, depth; L, maximum length; W, width.

hospitalization. ADHF was defined as new-onset decompensated heart failure or decompensation of chronic heart failure as previously described. ${ }^{15}$ Acute coronary syndrome was excluded. Heart failure (HF) was defined according to Framingham criteria, together with pulmonary congestion on X-rays or pulmonary hypertension as evaluated by Doppler echocardiography. The control group consisted of 32 age- and sex-matched patients without a previous history of HF who were hospitalized for inspection of the gastrointestinal tract or the liver. Patients with malignancy, a unilateral kidney, polycystic kidney disease, and those who received regular hemodialysis were excluded.

\section{Data collection}

Medical records were reviewed for demographics, laboratory data, echocardiograms, medications, and therapeutic response. All measurements were obtained on admission. Kidney volume was assessed by an abdominal US examination within 48 hours after hospitalization. The estimated glomerular filtration rate (eGFR) was determined by the modified Modification of Diet and
Renal Disease study formula for Japanese: eGFR=194 $\times$ $\left(\right.$ age $\left.^{-0.287}\right) \times\left(\right.$ serum creatinine $\left.{ }^{-1.094}\right) \times(0.739$ if female $) .{ }^{16}$ We defined the severity of chronic kidney disease (CKD) based on the guideline of $\mathrm{CKD}^{9}$ as follows: normal, eGFR $\geq 90 \mathrm{~mL} / \mathrm{min} / 1.73 \mathrm{~m}^{2}$; mild, eGFR $\geq 60$ and $<$ $90 \mathrm{~mL} / \mathrm{min} / 1.73 \mathrm{~m}^{2}$; moderate, eGFR $\geq 30$ and $<60$ $\mathrm{mL} / \mathrm{min} / 1.73 \mathrm{~m}^{2}$; and severe, eGFR $<30 \mathrm{~mL} / \mathrm{min} / 1.73$ $\mathrm{m}^{2}$. We evaluated the therapeutic response in the acute phase, including total urine volume, change in body weight, and improvement of New York Heart Association class and signs of congestion, during the first 3 days from admission. All of the patients received intravenous (i.v.) furosemide for 3 days. At our hospital, the initial i.v. dose of furosemide was $40 \mathrm{mg} / \mathrm{d}$ according to the European Society of Cardiology (ESC) guidelines. ${ }^{17}$ After judgement of response to furosemide every a few hours, the attending physician changed the i.v. dose of furosemide to maintain water balance appropriately.

The same quantity of oral diuretics before hospitalization was continued during this period. The dose of oral loop diuretics was converted to furosemide equivalents as follows: $60 \mathrm{mg}$ of azosemide $=40 \mathrm{mg}$ of furosemide. ${ }^{18,19}$ 
Total daily use of furosemide was defined as the i.v. dose of furosemide plus $0.5 \times$ oral dose of furosemide equivalents for 3 days, taking into account biological availability as previously described. ${ }^{20}$ We defined a high dose of furosemide as $\geq 51.7 \mathrm{mg} / \mathrm{d}$ or based on the median value of total daily use of furosemide. The patients were divided into two groups: low-dose group $(<51.7 \mathrm{mg} / \mathrm{d}, n=16)$ and high-dose group ( $\geq 51.7 \mathrm{mg} / \mathrm{d}, n=13$ ).

\section{Renal US examination}

All renal US examinations were performed using standard grayscale B-mode imaging on an Aplio 500 Ultrasound System (Toshiba Medical Systems, Tochigi, Japan) with a 3.5-MHz convex transducer. One experienced US physician measured all US parameters. Renal length measurements were performed with patients in the supine position using US. The maximum renal length (L) and width (W) were obtained from longitudinal images in planes ranging from sagittal to coronal. The depth (D) was obtained from transverse images of the mid-kidney acquired in the plane perpendicular to the longitudinal plane (Fig 1A).

Kidney volume was determined using the formula for an ellipsoid $(\pi / 6 \times \mathrm{L} \times \mathrm{W} \times \mathrm{D}),{ }^{21}$ and was adjusted for the individual's height as previously described. ${ }^{22}$

\section{Kidney volume as assessed by computed to- mography}

The accuracy of kidney volume as calculated with US was evaluated by comparing it with that assessed by computed tomography (CT). Eleven patients with ADHF underwent thoracic and abdominal $\mathrm{CT}$ to identify the cause of infection and pleural effusion on admission to hospital. In this study, we used a 3D-imaging analysis system (SYNAPSE VINCENT; Fuji Photo Film, Tokyo, Japan) to calculate bilateral kidney volume (Fig. 1B). This system is available for automatic extraction of organ and automatic volume measurement, and its application with organs of the whole body has been reported. ${ }^{23}$

This study conformed with the principles outlined in the Declaration of Helsinki and was approved by the institutional review board for human investigation at Tottori University Hospital (approval number: 2467). Written informed consent was provided by each subject.

\section{Statistical analysis}

Continuous variables are expressed as mean \pm standard deviation for normally distributed variables, and median and interquartile range for non-normally distributed variables. The normality of distribution was assessed by the Kolmogorov-Smirnov test. Differences in continu- ous variables between the two groups were compared using the $t$-test for normally distributed variables and the Mann-Whitney $U$ test for non-normally distributed variables. Categorical variables are expressed as percentages. Categorical variables were compared using Fisher's exact test. Correlations of continuous variables between the two groups were tested by Spearman's rank correlation coefficient and Bland-Altman plots. Multivariate logistic regression models were performed to assess the independent predictors of the requirement for high-dose furosemide. All baseline variables with $P<0.05$ in univariate analysis were entered into the analysis. A $P$ value $<0.05$ was considered significant. All analyses were performed using EZR (Saitama Medical Center, Jichi Medical University), which is a graphical user interface for R (The R Foundation for Statistical Computing, version 2.13.0), and XLSTAT for Microsoft Excel (Microsoft, Redmond, WA).

\section{RESULTS \\ Patients' characteristics between the control and ADHF groups}

The patients' characteristics in the ADHF group are shown in Tables 1 and 2. The mean age was $75 \pm 14$ years and $51.7 \%$ were men. The etiology of HF was ischemic heart disease in $24.1 \%$, valvular heart disease in $20.7 \%$, and cardiomyopathy in $24.1 \%$ of patients. Mean left ventricular ejection fraction was $44.2 \pm 18.5 \%$, and HF with preserved ejection fraction $(>45 \%)$ was prevalent in $44.8 \%$ of patients. More than half of the patients had New York Heart Association class IV and "warm and wet" as assessed by noninvasive classification of $\mathrm{ADHF}^{24}$

The patients' characteristics in the control group are shown in Table 1. The ADHF group had significantly higher levels of BUN and creatinine, and a lower eGFR compared with the control group (all $P<0.05$ ). There were no significant differences in other well-known factors related to kidney size, including age, sex, height, and body weight, as well as the prevalence of hypertension and diabetes, ${ }^{25}$ between the two groups.

\section{Kidney volume between the control and ADHF groups}

Figure 2 shows the correlation of kidney volume as assessed by US with that as assessed by CT. We found a good linear correlation between the two measurements in Spearman's rank correlation coefficient analysis (left: $r=0.979, P<0.001$; right: $r=0.973, P<0.001$, Fig. 2A). Bland-Altman plots showed that the mean difference in kidney volume between CT and US was $5.66 \mathrm{~mL}$ (left) and $2.62 \mathrm{~mL}$ (right), and the standard deviation was 
Table 1. Patients' characteristics in the control and ADHF groups

\begin{tabular}{|c|c|c|c|}
\hline & $\begin{array}{l}\text { control group } \\
(n=32)\end{array}$ & $\begin{array}{l}\text { ADHF group } \\
(n=29)\end{array}$ & $P$-value \\
\hline \multicolumn{4}{|l|}{ Demographics } \\
\hline Age (years) & $70 \pm 14$ & $75 \pm 14$ & 0.158 \\
\hline Male $(\%)$ & 65.6 & 51.7 & 0.278 \\
\hline Height $(\mathrm{cm})$ & $160.4 \pm 9.4$ & $159.6 \pm 8.7$ & 0.729 \\
\hline Body weight (kg) & $60.7 \pm 11.8$ & $59.3 \pm 15.5$ & 0.685 \\
\hline Systolic blood pressure (mmHg) & $130 \pm 21$ & $124 \pm 25$ & 0.509 \\
\hline Heart rate (beats/min) & $73 \pm 10$ & $85 \pm 20$ & 0.057 \\
\hline \multicolumn{4}{|l|}{ Comorbidity conditions } \\
\hline Hypertension (\%) & 56.5 & 62.1 & 0.651 \\
\hline Diabetes $(\%)$ & 28.1 & 34.5 & 0.600 \\
\hline Dyslipidemia (\%) & 50.0 & 31.0 & 0.350 \\
\hline Chronic obstructive disease (\%) & 22.6 & 20.7 & 0.862 \\
\hline \multicolumn{4}{|l|}{ Laboratory values } \\
\hline BUN (mmol/L) & $5.2 \pm 1.8$ & $9.2 \pm 6.2$ & 0.003 \\
\hline Creatinine (umol/L) & $72.4 \pm 22.0$ & $99.9 \pm 57.5$ & 0.015 \\
\hline eGFR (mL /min/1.73 m²) & $71.0 \pm 24.1$ & $53.2 \pm 22.4$ & 0.004 \\
\hline Severity of CKD: & & & 0.005 \\
\hline Normal/mild/moderate/severe (\%) & $18.8 / 43.8 / 37.4 / 0.0$ & 6.9/27.6/55.2/10.3 & \\
\hline
\end{tabular}

Data are mean \pm SD or percentage. Severity of CKD was classified as follows: normal, eGFR $\geq 90 \mathrm{~mL} / \mathrm{min} / 1.73 \mathrm{~m}$; $\mathrm{mild}$, eGFR $\geq 60$ and $<90 \mathrm{~mL} / \mathrm{min} / 1.73 \mathrm{~m}^{2}$; moderate, eGFR $\geq 30$ and $<60 \mathrm{~mL} / \mathrm{min} / 1.73 \mathrm{~m}^{2}$; and severe, eGFR $<30 \mathrm{~mL} / \mathrm{min} / 1.73 \mathrm{~m}^{2}$.

$\mathrm{ADHF}$, acute decompensated heart failure; BUN, blood urea nitrogen; CKD, chronic kidney disease; eGFR, estimated glomerular rate.

\section{Left Kidney Volume}

\section{A Spearman rank correlation analysis}

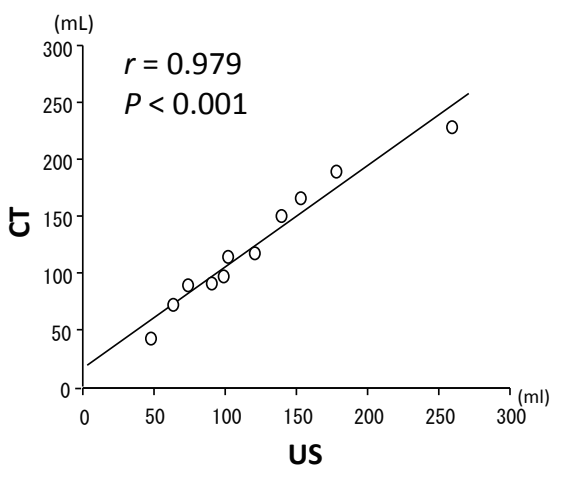

\section{B Bland-Altman plot}

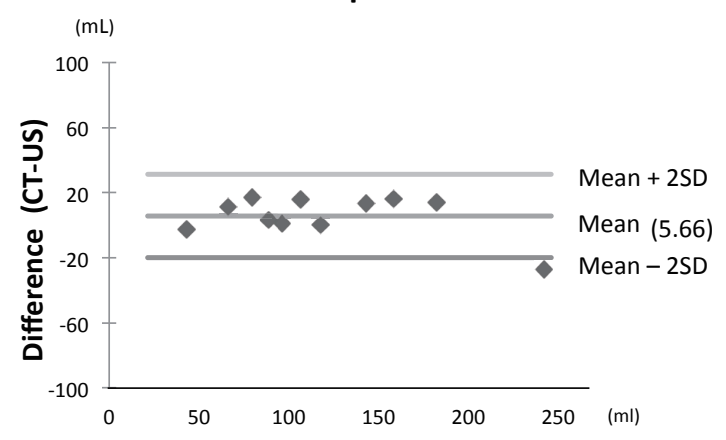

Average of US and CT

\section{Right Kidney Volume}
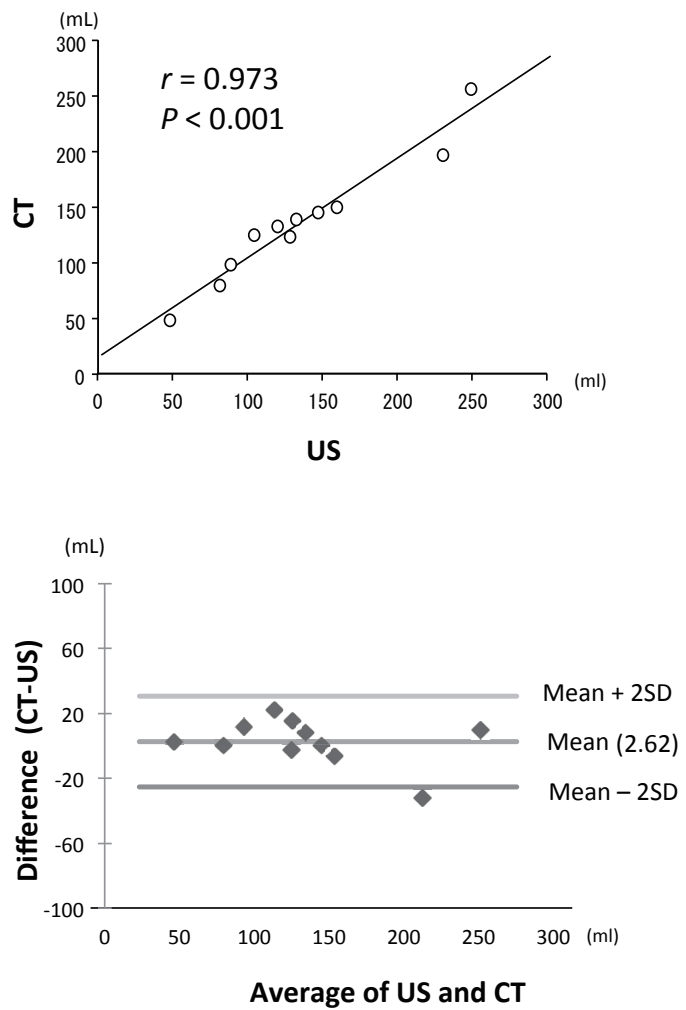

Fig. 2. Correlation of kidney volume calculated by US and CT. A: Spearman's rank correlation coefficient analysis of the left and right kidneys. B: Bland-Altman plots of the left and right kidneys. The mean differences in the volume of CT and US were $5.66 \mathrm{~mL}$ (left) and 2.62 $\mathrm{mL}$ (right), and the SD was $13.45 \mathrm{~mL}$ (left) and $14.28 \mathrm{~mL}$ (right). CT, computed tomography; US, ultrasound. 
Table 2. Baseline characteristics of patients with ADHF in the low-dose and high-dose furosemide groups

\begin{tabular}{|c|c|c|c|}
\hline & $\begin{array}{l}\text { Low dose group } \\
(n=16)\end{array}$ & $\begin{array}{l}\text { High dose group } \\
(n=13)\end{array}$ & $P$-value \\
\hline \multicolumn{4}{|l|}{ Demographics } \\
\hline Age (years) & $74 \pm 13$ & $76 \pm 16$ & 0.771 \\
\hline Male (\%) & 62.5 & 38.5 & 0.211 \\
\hline Prior heart failure hospitalization (\%) & 43.7 & 46.2 & 0.902 \\
\hline Height $(\mathrm{cm})$ & $161.4 \pm 7.9$ & $157.5 \pm 9.5$ & 0.240 \\
\hline Body weight (kg) & $61.4 \pm 18.4$ & $56.7 \pm 11.1$ & 0.413 \\
\hline Systolic blood pressure (mmHg) & $120 \pm 23$ & $129 \pm 28$ & 0.322 \\
\hline Heart rate (beats/min) & $85 \pm 16$ & $87 \pm 25$ & 0.785 \\
\hline NYHA class III/IV (\%) & $75.0 / 25.0$ & $61.5 / 38.5$ & 0.454 \\
\hline \multicolumn{4}{|l|}{ Noninvasive classification of ADHF: } \\
\hline Warm/cold, wet/dry & $75.0 / 25.0,100.0 / 0.0$ & $84.6 / 15.4,84.6 / 15.4$ & $0.542 / 0.111$ \\
\hline Clinical scenario: $1 / 2 / 3 / 5$ & 25.0/43.8/12.5/18.7 & 23.1/69.2/7.7/0.0 & 0.686 \\
\hline $\operatorname{LVEF}(\%)$ & $46.0 \pm 20.6$ & $44.1 \pm 16.0$ & 0.782 \\
\hline \multicolumn{4}{|l|}{ Comorbidities } \\
\hline Coronary artery disease $(\%)$ & 18.8 & 30.8 & 0.470 \\
\hline Hypertension (\%) & 62.5 & 61.5 & 0.959 \\
\hline Diabetes (\%) & 23.1 & 33.3 & 0.587 \\
\hline \multicolumn{4}{|l|}{ Laboratory values } \\
\hline Sodium (mmol/L) & $138.8 \pm 4.6$ & $142.0 \pm 5.9$ & 0.113 \\
\hline Albumin (g/L) & $32.7 \pm 7.5$ & $35.2 \pm 6.7$ & 0.390 \\
\hline $\mathrm{BNP}(\mathrm{pg} / \mathrm{mL})$ & $1256(480-1437)$ & 1015 (318-1218) & 0.548 \\
\hline BUN (mmol/L) & $7.5 \pm 2.6$ & $11.3 \pm 8.7$ & 0.100 \\
\hline Creatinine (umol/L) & $82.2 \pm 26.5$ & $121.1 \pm 76.6$ & 0.068 \\
\hline eGFR $\left(\mathrm{mL} / \mathrm{min} / 1.73 \mathrm{~m}^{2}\right)$ & $60.8 \pm 21.6$ & $43.9 \pm 20.4$ & 0.040 \\
\hline Severity of CKD: & & & \\
\hline Normal/mild/moderate/severe (\%) & $12.5 / 31.3 / 56.2 / 0.0$ & $0.0 / 15.4 / 61.5 / 23.1$ & 0.018 \\
\hline \multicolumn{4}{|l|}{ Pre-hospital medication } \\
\hline ACEI/ARB (\%) & 50.0 & 58.3 & 0.685 \\
\hline$\beta$-blocker (\%) & 38.5 & 50.0 & 0.580 \\
\hline MRA (\%) & 12.5 & 15.4 & 0.830 \\
\hline Loop diuretics $(\%)$ & 31.3 & 76.9 & 0.013 \\
\hline Thiazide (\%) & 12.5 & 7.7 & 0.686 \\
\hline Tolvaptan (\%) & 0.0 & 0.0 & 1.000 \\
\hline
\end{tabular}

Data are mean $\pm \mathrm{SD}$ or median (interquartile range). Severity of CKD was classified as follows: normal, eGFR $\geq 90 \mathrm{~mL} / \mathrm{min} / 1.73 \mathrm{~m}{ }^{2}$; mild, eGFR $\geq 60$ and $<90 \mathrm{~mL} / \mathrm{min} / 1.73 \mathrm{~m}^{2}$; moderate, eGFR $\geq 30$ and $<60 \mathrm{~mL} / \mathrm{min} / 1.73 \mathrm{~m}^{2}$; and severe, eGFR $<30 \mathrm{~mL} / \mathrm{min}^{2} 1.73 \mathrm{~m}{ }^{2}$. ACEI, angiotensin-converting enzyme inhibitor; ADHF, acute decompensated heart failure; ARB, angiotensin receptor blocker; BNP, B-type natriuretic peptide; BUN, blood urea nitrogen; CKD, chronic kidney disease; eGFR, estimated glomerular filtration rate; LVEF, left ventricular ejection fraction; MRA, mineralocorticoid receptor antagonist; NYHA, New York Heart Association.

$13.45 \mathrm{~mL}$ (left) and $14.28 \mathrm{~mL}$ (right, Fig. 2B).

Figure 3 shows the height-adjusted kidney volume of the control and ADHF groups. Left kidney volume in the ADHF group was significantly lower than that in the control group $(27.7 \pm 10.0 \mathrm{~mL} / \mathrm{m}$ vs. $32.8 \pm 8.8 \mathrm{~mL} / \mathrm{m}, P$ $<0.05)$. Right kidney volume and the mean left and right kidney volumes in the ADHF group were also slightly smaller than those in the control group, but they did not reach significance $(29.4 \pm 8.2 \mathrm{~mL} / \mathrm{m}$ vs. $31.5 \pm 11.0 \mathrm{~mL} /$ $\mathrm{m}, P=0.412,28.6 \pm 8.1 \mathrm{~mL} / \mathrm{m}$ vs. $32.1 \pm 9.0 \mathrm{~mL} / \mathrm{m}, P=$ 0.110 , respectively).

\section{Characteristics of patients with ADHF in the low- dose and high-dose furosemide groups}

Table 2 shows baseline characteristics of patients with ADHF between the low-dose and high-dose groups. Patients in the high-dose group had a significantly lower level of eGFR than did those in the low-dose group $(P<$ 0.05). Serum levels of BUN and creatinine also tended to be higher in the high-dose group than in the low-dose group. The prescription rate of oral loop diuretics before hospital admission was significantly higher in the highdose group than in the low-dose group $(P<0.05)$. There were no significant differences in age, sex, height, body 

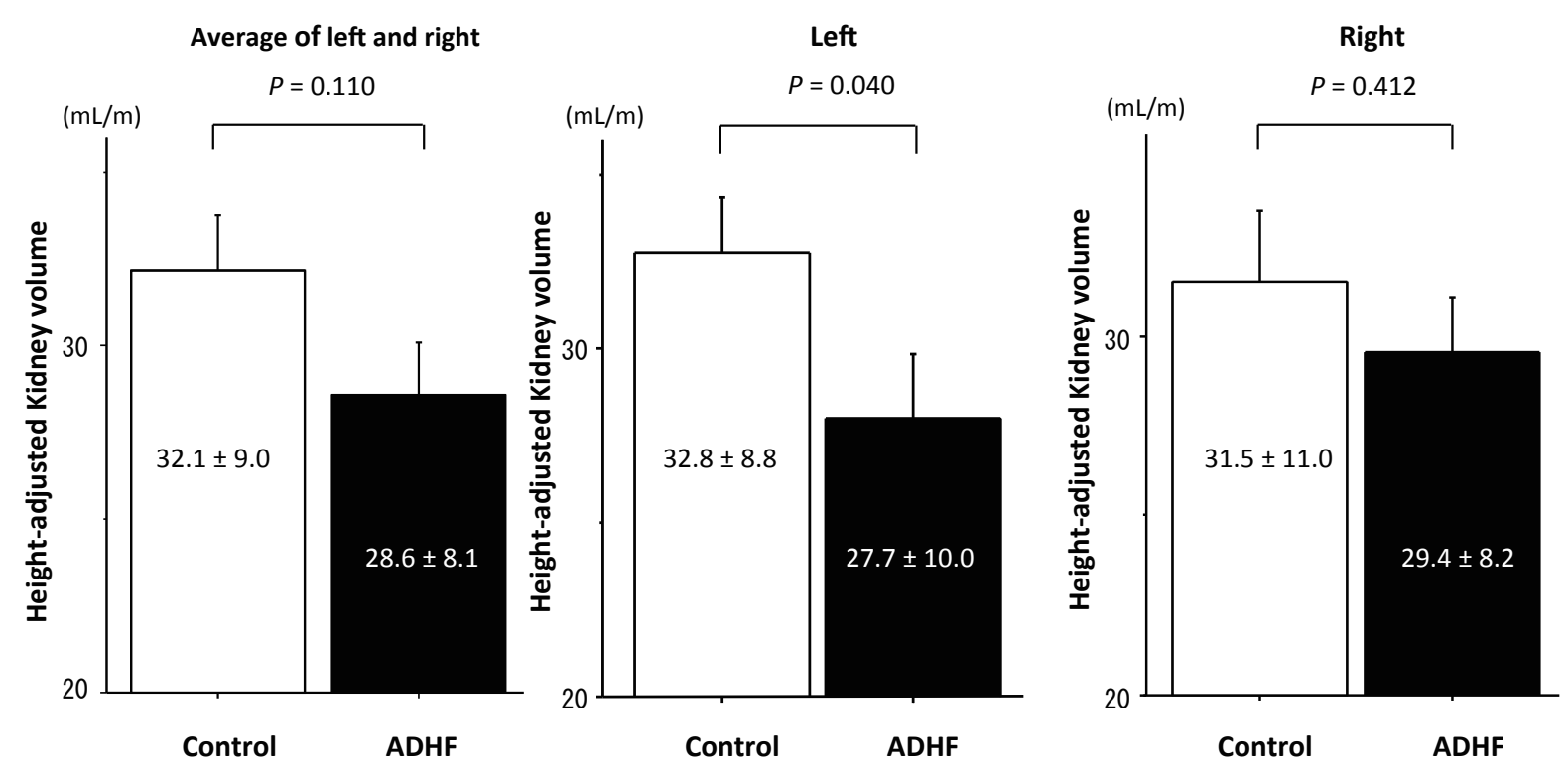

Fig. 3. Height-adjusted kidney volume in the control and ADHF groups. Patients in the ADHF group had a significantly smaller left kidney volume than those in the control group. ADHF, acute decompensated heart failure.

weight, medical history, and other laboratory data between the two groups.

\section{In-hospital treatment and therapeutic response in ADHF in the low-dose and high-dose furosemide groups}

Table 3 shows the in-hospital treatment and therapeutic responses during 3 days after admission to hospital. All of the patients received i.v. furosemide for 3 days, and the daily mean i.v. dose was $37.4 \pm 18.4 \mathrm{mg} / \mathrm{d}(20-100.0$ $\mathrm{mg} / \mathrm{d})$. The dose of oral diuretics prescribed before hospitalization was not changed during this period, and the daily oral dose was $43.3 \pm 23.8 \mathrm{mg} / \mathrm{d}(20.0-120.0 \mathrm{mg} / \mathrm{d})$. Patients in the high-dose group more frequently received a higher daily dose of i.v. furosemide ( $47.4 \pm 18.1$ vs. $26.3 \pm 11.9 \mathrm{mg} / \mathrm{d}, P<0.05)$, as well as a higher daily dose of oral furosemide $(56.9 \pm 24.3$ vs. $32.2 \pm 17.2$ $\mathrm{mg} / \mathrm{d}, P<0.05)$, compared with those in the low-dose group. Additionally, patients in the high-dose group had a higher prescription rate and dosage of carperitide than did those in the low-dose group (92.3\% vs. $56.3 \%, 0.021$ \pm 0.01 vs. $0.010 \pm 0.001 \gamma$, all $P<0.05$ ). There were no significant differences in therapeutic responses, including a change in body weight, total urine volume, and improvement of symptoms and congestion between the two groups. Therefore, patients in the high-dose group required more intensive decongestion therapy for the same degree of improvement compared with the lowdose group.
Kidney volume in ADHF in the low-dose and highdose furosemide groups

Figure 4 shows kidney volume in ADHF between the low-dose and high-dose groups. Left and right kidney volumes in the high-dose group were significantly smaller than those in the low-dose group (left: $23.2 \pm 5.2$ vs. $32.6 \pm 11.0 \mathrm{~mL} / \mathrm{m}$, right: $26.5 \pm 7.5$ vs. $32.6 \pm 7.9 \mathrm{~mL} / \mathrm{m}$, mean of both sides: $24.9 \pm 3.9$ vs. $32.6 \pm 8.9 \mathrm{~mL} / \mathrm{m}$, all $P$ $<0.05)$.

Table 4 shows multivariate logistic regression analysis for predicting the requirement of high-dose furosemide. In univariate analysis, eGFR and each kidney volume were significantly associated with high-dose furosemide. In multivariate analysis, left kidney volume, but not eGFR, remained an independent predictor of the requirement of high-dose furosemide (odds ratio: 0.856, 95\% confidence interval: $0.735-0.997, P<0.05$ ) (Table 4).

\section{DISCUSSION}

This study showed that kidney volume as assessed by US independently predicted the required dose of furosemide at the acute phase of treatment of ADHF.

Renal function is one of the determinants of a diuretic response in $\mathrm{ADHF}^{4-8}{ }^{4}$ However, in ADHF, several factors affect the value of renal function tests. Creatinine levels and eGFR are affected by fluid retention or a decrease in blood pressure. ${ }^{10}$ The level of BUN, a marker of reduced glomerular filtration, ${ }^{26}$ is also affected by comorbidities, such as liver disease and malnutrition. ${ }^{27}$ The 
Table 3. In-hospital management, and therapeutic response of ADHF in the low-dose and high-dose furosemide groups

\begin{tabular}{|c|c|}
\hline $\begin{array}{l}\text { Low dose group } \\
(n=16)\end{array}$ & $\begin{array}{l}\text { High dose group } \\
(n=13)\end{array}$ \\
\hline
\end{tabular}

\begin{tabular}{|c|c|c|c|}
\hline \multicolumn{4}{|l|}{ Furosemide } \\
\hline Daily i.v. dose (mg/day) & $26.3 \pm 11.9$ & $47.4 \pm 18.1$ & 0.001 \\
\hline Daily oral dose (mg/day) & $32.2 \pm 17.2$ & $56.9 \pm 24.3$ & 0.003 \\
\hline Daily total dose (i.v. dose conversion) (mg/day) & $42.5 \pm 8.6$ & $75.9 \pm 18.7$ & $<0.001$ \\
\hline \multicolumn{4}{|l|}{ Intravenous drugs } \\
\hline Carperitide (\%) & 56.3 & 92.3 & 0.031 \\
\hline Mean dose of carperitide $(\gamma)$ & $0.010 \pm 0.001$ & $0.021 \pm 0.010$ & 0.030 \\
\hline Nitroglycerin $(\%)$ & 12.5 & 15.4 & 0.830 \\
\hline Inotropes $(\%)$ & 12.5 & 23.1 & 0.471 \\
\hline \multicolumn{4}{|l|}{ Non-pharmacological management } \\
\hline NPPV (\%) & 25.0 & 38.5 & 0.454 \\
\hline Intubation $(\%)$ & 0.0 & 0.0 & 1.000 \\
\hline IABP/PCPS (\%) & 0.0 & 0.0 & 1.000 \\
\hline Ultrafiltration (\%) & 0.0 & 0.0 & 1.000 \\
\hline \multicolumn{4}{|l|}{ Therapeutic response } \\
\hline Daily change in body weight, (kg/day) & $-0.7 \pm 0.5$ & $-0.8 \pm 0.5$ & 0.727 \\
\hline Daily urine volume, (mL/day) & $2066 \pm 683$ & $2012 \pm 724$ & 0.841 \\
\hline $\begin{array}{l}\text { Improvement of: } \\
\text { NYHA class (\%) }\end{array}$ & 87.5 & 69.2 & 0.242 \\
\hline Peripheral edema $(\%)$ & 50.0 & 30.8 & 0.374 \\
\hline Rales (\%) & 43.8 & 46.2 & 0.902 \\
\hline JVD $(\%)$ & 18.8 & 15.4 & 0.820 \\
\hline
\end{tabular}

Data are mean \pm SD or percentage.

ADHF, acute decompensated heart failure; IABP, intra-aortic balloon pumping; i.v., intravenous; JVD, jugular vein dilatation; NPPV, noninvasive positive pressure ventilation; NYHA, New York Heart Association; PCPS, percutaneous cardiopulmonary support.
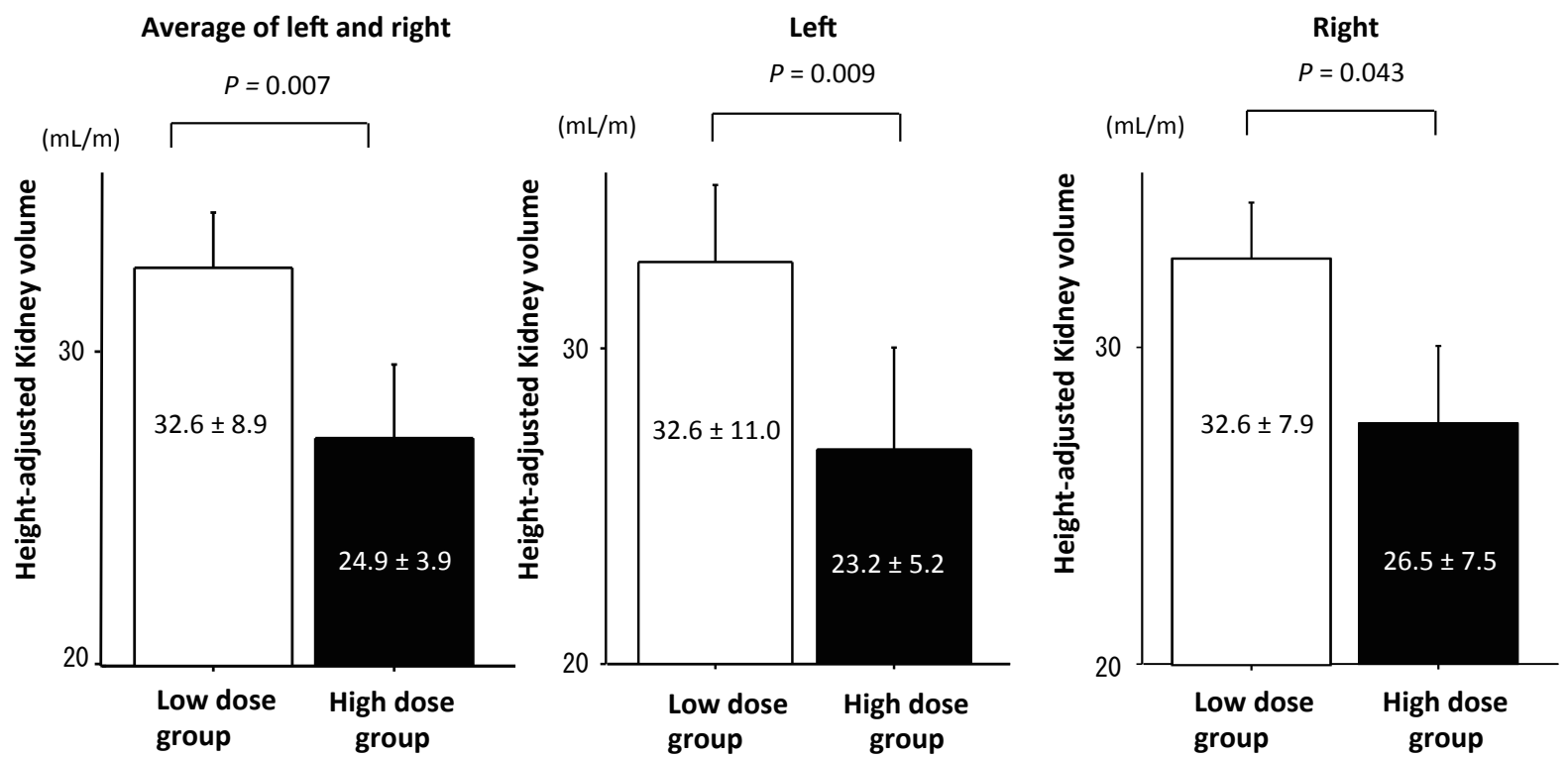

Fig. 4. Height-adjusted kidney volume of ADHF in the low-dose and high-dose furosemide groups. Patients in the high-dose group had a significantly smaller kidney volume (left, right) than those in the low-dose group. ADHF, acute decompensated heart failure. 
Table 4. Multivariable logistic regression analyses for predicting the requirement of high-dose furosemide

\begin{tabular}{lllc}
\hline & OR & $95 \%$ CI & $P$-value \\
\hline Average of left and right kidney volume & 0.831 & $0.688-1.004$ & 0.055 \\
eGFR & 0.973 & $0.927-1.021$ & 0.263 \\
Left kidney volume & 0.856 & $0.735-0.997$ & 0.045 \\
eGFR & 0.969 & $0.925-1.016$ & 0.195 \\
Right kidney volume & 0.921 & $0.821-1.034$ & 0.163 \\
eGFR & 0.966 & $0.921-1.012$ & 0.149 \\
\hline
\end{tabular}

$\mathrm{CI}$, confidence interval; eGFR, estimated glomerular filtration rate; OR, odds ratio.

present study showed that, among renal biomarkers, only eGFR was significantly associated with a requirement for a high dose of furosemide. However, by multivariate analysis, eGFR no longer independently predicted diuretic resistance. This finding suggested insufficiency of these conventional markers in identifying patients at a high risk for diuretic resistance.

Kidney volume is a simple estimate of renal reserve and function. ${ }^{13}$ Some studies have shown that kidney volume provides useful information on the risk and complications in CKD beyond eGFR and albuminuria. ${ }^{13,28} \mathrm{~A}$ previous study on ADHF reported that a shorter longitudinal kidney length as assessed by CT was associated with a poor diuretic response. ${ }^{29}$ In this study, we showed the reliability of US in the measurement of kidney volume compared with CT. US has the advantage of no radiation exposure and can be conducted at the bedside. Therefore, the current study expanded previous findings by demonstrating that kidney volume as assessed by US is a convenient and noninvasive alternative to that as assessed by $\mathrm{CT}$ for identifying patients at high risk for diuretic resistance.

Interestingly we found that, in patients with ADHF, left kidney atrophy was predominantly observed, and was independently associated with diuretic resistance. Although this study had a small sample size, and cannot provide conclusive evidence, we speculate several possible mechanisms regarding the relation between the laterality of kidney size and the diuretic response. Davran et al. previously reported that there was a higher prevalence of left kidney atrophy than right kidney atrophy. Of 2417 patients, $1.3 \%$ of patients had renal atrophy in the left side compared with $0.2 \%$ of patients with renal atrophy in the right side. ${ }^{30}$ The cause of left kidney atrophy is unclear, but a potential explanation is anatomical differences in the kidney. The left renal artery is shorter than the right renal artery because of the location of the aorta. ${ }^{31}$ Davran et al. speculated that the left kidney is likely to receive a relatively high arterial pressure because of the shorter distance to the heart. ${ }^{30}$ This results in endothelial dysfunction and atherosclerosis, which cause poor perfusion of the left kidney. ${ }^{31,32}$ Additionally, the left kidney is in contact with many organs, including the aorta, pancreas, spleen, stomach, small intestine, and colon. However, the right kidney contacts only three organs of the liver, right colon flexure, and duodenum. ${ }^{31}$ In ADHF, venous congestion elevates intra-abdominal pressure (IAP)..$^{33}$ The left kidney is more likely to be compressed by elevated IAP than the right kidney because many organs around the left kidney may form a close space and increase local IAP. Additionally, the left renal vein is approximately two or three times longer than the right renal vein, and is in contact with the aorta. ${ }^{31}$ Elevated IAP may also lead to left renal vein compression and congestion, ${ }^{34}$ contributing to poor left kidney perfusion and worsened renal function. The dominancy of left kidney atrophy remains a matter of speculation. Further investigations are necessary to evaluate the relationship between the laterality of kidney size and renal function.

This study has several limitations. First, there is a large difference in the dose of furosemide used between our study and previous studies conducted in Western countries. A dose trial showed that the daily dose of i.v. furosemide at the acute phase of treatment was approximately $120 \mathrm{mg} / \mathrm{d}$ in the low-dose group and $260 \mathrm{mg} /$ $\mathrm{d}$ in the high-dose group. ${ }^{35}$ However, patients with HF in Japan require a lower dose of furosemide than those in Western countries. A phase III, randomized, double-blind, placebo-controlled study (QUEST study) assessed the efficiency and safety of tolvaptan in Japanese patients with ADHF. ${ }^{36}$ This previous study showed that volume overload, despite the use of an average daily dose of furosemide $\geq 40 \mathrm{mg}$, is defined as diuretic resistance. In our study, patients in the high-dose group received a high dose of furosemide of $\geq 40 \mathrm{mg} / \mathrm{d}$ (daily oral dose of $56.9 \pm 24.3 \mathrm{mg} / \mathrm{d}$ plus a daily i.v. dose of $47.4 \pm 18.1 \mathrm{mg} /$ d), which indicated that they were accompanied by diuretic resistance. Second, this study had a small sample size and low statistical power. Furthermore, the effect of kidney volume on clinical outcomes was unclear. Fur- 
ther well-designed, large, prospective trials are required to clarify these issues. In conclusions, Kidney volume as assessed by US is helpful in identifying patients with $\mathrm{ADHF}$ at a high risk for diuretic resistance.

The authors declare no conflict of interest.

\section{REFERENCES}

1 Metra M, Cleland JG, Weatherley BD, Dittrich HC, Givertz MM, Massie BM, et al. Dyspnoea in patients with acute heart failure: an analysis of its clinical course, determinants, and relationship to 60-day outcomes in the PROTECT pilot study. Eur J Heart Fail. 2010;12:499-507. PMID: 20228387.

2 Metra M, Teerlink JR, Felker GM, Greenberg BH, Filippatos G, Ponikowski P, et al. Dyspnoea and worsening heart failure in patients with acute heart failure: results from the PreRELAX-AHF study. Eur J Heart Fail. 2010;12:1130-9. PMID: 20732868.

3 Adams KF Jr, Fonarow GC, Emerman CL, LeJemtel TH, Costanzo MR, Abraham WT, et al. Characteristics and outcomes of patients hospitalized for heart failure in the United States: rationale, design, and preliminary observations from the first 100,000 cases in the Acute Decompensated Heart Failure National Registry (ADHERE). Am Heart J. 2005;149:209-16. PMID: 15846257.

4 Adams KF Jr, Fonarow GC, Emerman CL, LeJemtel TH, Costanzo MR, Abraham WT, et al. Prospective Randomized Amlodipine Survival Evaluation. Diuretic resistance predicts mortality in patients with advanced heart failure. Am Heart J. 2002;144:31-8. PMID: 15846257.

5 Testani JM, Brisco MA, Turner JM, Spatz ES, Bellumkonda L, Parikh CR, et al. Loop diuretic efficiency: a metric of diuretic responsiveness with prognostic importance in acute decompensated heart failure. Circ Heart Fail. 2014;7:261-70. PMID: 24379278.

6 ter Maaten JM, Dunning AM, Valente MA, Damman K, Ezekowitz JA, Califf RM, et al. Diuretic response in acute heart failure-an analysis from ASCEND-HF. Am Heart J. 2015;170:313-21. PMID: 26299229.

7 Valente MA, Voors AA, Damman K, Van Veldhuisen DJ, Massie BM, O'Connor CM et al. Diuretic response in acute heart failure: clinical characteristics and prognostic significance. Eur Heart J. 2014;35:1284-93. PMID: 24585267.

8 Voors AA, Davison BA, Teerlink JR, Felker GM, Cotter G, Filippatos G, et al. Diuretic response in patients with acute decompensated heart failure: characteristics and clinical outcome--an analysis from RELAX-AHF. Eur J Heart Fail. 2014;16:1230-40. PMID: 25287144.

9 National Kidney Foundation. K/DOQI clinical practice guidelines for chronic kidney disease: evaluation, classification, and stratification. Am J Kidney Dis. 2002;39 Suppl 1:S1-266. PMID: 11904577.

10 Imamura T, Kinugawa K, Shiga T, Kato N, Muraoka H, Minatsuki S, et al. Novel criteria of urine osmolality effectively predict response to tolvaptan in decompensated heart failure patients--association between non-responders and chronic kidney disease. Circ J. 2013;77:397-404. PMID: 23131721.

11 Dupont M, Mullens W, Finucan M, Taylor DO, Starling RC, Tang WH. Determinants of dynamic changes in serum creatinine in acute decompensated heart failure: the importance of blood pressure reduction during treatment. Eur J Heart Fail. 2013;15:433-40. PMID: 23288912.

12 Testani JM, Hanberg JS, Cheng S, Rao V, Onyebeke C, Laur $\mathrm{O}$ et al. Rapid and Highly Accurate Prediction of Poor Loop Diuretic Natriuretic Response in Patients With Heart Failure. Circ Heart Fail. 2016;9:e002370. PMID: 26721915.

13 Aronson D, Burger AJ. Diuretic Response: Clinical and Hemodynamic Predictors and Relation to Clinical Outcome. J Card Fail. 2016;22:193-200. PMID: 26209003.

14 Moghazi S, Jones E, Schroepple J, Arya K, McClellan W, Hennigar RA et al. Correlation of renal histopathology with sonographic findings. Kidney Int. 2005;67:1515-20. PMID: 15780105.

15 Hirai M, Kato M, Kinugasa Y, Sugihara S, Yanagihara K, Yamada $\mathrm{K}$, et al. Clinical scenario 1 is associated with winter onset of acute heart failure. Circ J. 2015;79:129-35. PMID: 25421314.

16 Matsuo S, Imai E, Horio M, Yasuda Y, Tomita K, Nitta K, et al.; Collaborators developing the Japanese equation for estimated GFR. Revised equations for estimated GFR from serum creatinine in Japan. Am J Kidney Dis. 2009;53:982-92. PMID: 19339088.

17 Ponikowski P, Voors AA, Anker SD, Bueno H, Cleland JG, Coats AJ,et al. Document Reviewers.2016 ESC Guidelines for the diagnosis and treatment of acute and chronic heart failure: The Task Force for the diagnosis and treatment of acute and chronic heart failure of the European Society of Cardiology (ESC). Developed with the special contribution of the Heart Failure Association (HFA) of the ESC. Eur J Heart Fail. 2016;18:891-975. PMID: 27207191.

18 Krück F, Bablok W, Besenfelder E, Betzien G, Kaufmann B. Clinical and pharmacological investigations of the new saluretic azosemid. Eur J Clin Pharmacol. 1978;14:153-61. PMID: 729610.

19 J-MELODIC Program Committee. Rationale and design of a randomized trial to assess the effects of diuretics in heart failure: Japanese Multicenter Evaluation of Long- vs Short-Acting Diuretics in Congestive Heart Failure (J-MELODIC). Circ J. 2007;71:1137-40. PMID: 17587724.

20 Hammarlund MM, Paalzow LK, Odlind B. Pharmacokinetics of furosemide in man after intravenous and oral administration. Application of moment analysis. Eur J Clin Pharmacol. 1984;26:197-207. PMID: 6723758.

21 O’Neill WC, Robbin ML, Bae KT, Grantham JJ, Chapman AB, Guay-Woodford LM, et al. Sonographic assessment of the severity and progression of autosomal dominant polycystic kidney disease: the Consortium of Renal Imaging Studies in Polycystic Kidney Disease (CRISP). Am J Kidney Dis. 2005;46:1058-64. PMID: 16310571.

22 Chapman AB, Bost JE, Torres VE, Guay-Woodford L, Bae KT, Landsittel D, et al. Kidney volume and functional outcomes in autosomal dominant polycystic kidney disease. Clin J Am Soc Nephrol. 2012;7:479-86. PMID: 22344503.

23 Mochizuki K, Takatsuki M, Soyama A, Hidaka M, Obatake M, Eguchi S. The usefulness of a high-speed 3D-image analysis system in pediatric living donor liver transplantation. Ann Transplant. 2012;17:31-4. PMID: 22466906.

24 Nohria A, Lewis E, Stevenson LW. Medical management of advanced heart failure. JAMA. 2002;287:628-40. PMID: 11829703.

25 Buchholz NP, Abbas F, Biyabani SR, Afzal M, Javed Q, Rizvi I, et al. Ultrasonographic renal size in individuals without known renal disease. J Pak Med Assoc. 2000;50:12-6. PMID: 
10770041.

26 Kazory A. Emergence of blood urea nitrogen as a biomarker of neurohormonal activation in heart failure. Am J Cardiol. 2010;106: 694-700. PMID: 20723648.

27 Acchiardo SR, Moore LW, Latour PA. Malnutrition as the main factor in morbidity and mortality of hemodialysis patients. Kidney Int. 1983;Suppl 16: S199-203. PMID: 6429404.

28 Valente MA, Damman K, Dunselman PH, Hillege HL, Voors AA. Urinary proteins in heart failure. Prog Cardiovasc Dis. 2012;55:44-55. PMID: 22824109.

29 Toda H, Nakamura K, Nakahama M, Wada T, Watanabe A, Hashimoto K, et al. Clinical characteristics of responders to treatment with tolvaptan in patients with acute decompensated heart failure: Importance of preserved kidney size. J Cardiol. 2016;67:177-83. PMID: 26072263.

30 Davran R, Helvaci MR, Davarci M. Left renal atrophy. Int J Clin Exp Med. 2014;7:1603-6. PMID: 25035786.

31 Klatte T, Ficarra V, Gratzke C, et al. A Literature Review of Renal Surgical Anatomy and Surgical Strategies for Partial Nephrectomy. Eur Urol. 2015;68:980-92. PMID: 25911061.

32 Klatte T, Ficarra V, Gratzke C, Kaouk J, Kutikov A, Macchi
$\mathrm{V}$, et al. Risk of atrophy in kidneys with atherosclerotic renal artery stenosis. Kidney Int. 1998;53:735-42. PMID: 25911061.

33 Mullens W, Abrahams Z, Skouri HN, Francis GS, Taylor DO, Starling RC, et al. Elevated intra-abdominal pressure in acute decompensated heart failure: a potential contributor to worsening renal function? J Am Coll Cardiol. 2008;51:300-6. PMID: 18206740.

34 Scher KS, Coil JA Jr, Dawson DL, Wroczynski AF. The fate of the left kidney after division of its vein. Am Surg. 1984;50:613-6. PMID: 6497185.

35 Felker GM, Lee KL, Bull DA, Redfield MM, Stevenson LW, Goldsmith SR, et al. Diuretic strategies in patients with acute decompensated heart failure. N Engl J Med. 2011;364:797805. PMID: 21366472.

36 Matsuzaki M, Hori M, Izumi T, Fukunami M. Efficacy and safety of tolvaptan in heart failure patients with volume overload despite the standard treatment with conventional diuretics: a phase III, randomized, double-blind, placebo-controlled study (QUEST study). Cardiovasc Drugs Ther. 2011; 25 Suppl 1:S33-45. PMID: 22120092. 